Trinity University

Digital Commons @ Trinity

Chemistry Faculty Research

Chemistry Department

5-11-2010

\title{
Ultrafast Optical Study of Small Gold Monolayer Protected Clusters: A Closer Look at Emission
}

\author{
S. Hei Yau
}

O. Varnavski

John D. Gilbertson

Trinity University

Bert D. Chandler

Trinity University, bchandle@trinity.edu

G. Ramakrishna

See next page for additional authors

Follow this and additional works at: https://digitalcommons.trinity.edu/chem_faculty

Part of the Chemistry Commons

\section{Repository Citation}

Yau, S. H., Varnavski, O., Gilbertson, J. D., Chandler, B., Ramakrishna, G., \& Goodson III, T. (2010). Ultrafast optical study of small gold monolayer protected clusters: A closer look at emission. Journal of Physical Chemistry C, 114(38), 15979-15985.

This Article is brought to you for free and open access by the Chemistry Department at Digital Commons @ Trinity. It has been accepted for inclusion in Chemistry Faculty Research by an authorized administrator of Digital Commons @ Trinity. For more information, please contact 
Authors

S. Hei Yau, O. Varnavski, John D. Gilbertson, Bert D. Chandler, G. Ramakrishna, and T. Goodson 


\title{
Ultrafast Optical Study of Small Gold Monolayer Protected Clusters: A Closer Look at Emission ${ }^{\dagger}$
}

\author{
Sung Hei Yau, ${ }^{\ddagger}$ Oleg Varnavski, ${ }^{\ddagger}$ John D. Gilbertson, ${ }^{\S, \perp}$ Bert Chandler, ${ }^{\S}$ Guda Ramakrishna," \\ and Theodore Goodson III*, \\ Department of Chemistry, University of Michigan, Ann Arbor, Michigan 48109, Department of Chemistry, \\ Trinity University, 715 Stadium Drive, San Antonio, Texas 78212, and Department of Chemistry, Western \\ Michigan University, Kalamazoo, Michigan 49008-5413
}

Received: February 15, 2010; Revised Manuscript Received: May 11, 2010

\begin{abstract}
Monolayer-protected metal nanoclusters (MPCs) were investigated to probe their fundamental excitation and emission properties. In particular, gold MPCs were probed by steady-state and time-resolved spectroscopic measurements; the results were used to examine the mechanism of emission in relation to the excited states in these systems. In steady-state measurements, the photoluminescence of gold clusters in the range of 25 to 140 atoms was considerably stronger relative to larger particle analogues. The increase in emission efficiency (for $\mathrm{Au}_{25}, \mathrm{Au}_{55}$, and $\mathrm{Au}_{140}$ on the order of $10^{-5}$ ) over bulk gold may arise from a different mechanism of photoluminescence, as suggested by measurements on larger gold spheres and rods. Results of fluorescence upconversion found considerably longer lifetimes for smaller gold particles than for larger particles. Measurements of the femtosecond transient absorption of the smaller clusters suggested dramatically different behavior than what was observed for larger particles. These results, combined with the result of a new bleach band in the transient absorption signal (which is presumably due to an unforeseen ground state absorption), suggest that quantum size effects and associated discrete molecular-like state structure play a key role in enhanced visible fluorescence of small clusters.
\end{abstract}

\section{Introduction}

Metal nanoparticles have captured the attention of the research community in the past decade with their tunable physical and chemical properties. ${ }^{1-8}$ These materials hold great potential in a wide range of applications, including highly efficient catalysts, ${ }^{9-15}$ medical imaging markers, ${ }^{16,17}$ and various molecular electronics. ${ }^{4,9,18,19}$ There has been a great deal of optical and electronic investigation of the specific properties of nanoparticles at various sizes. Bulk metal, metal thin films, nanoparticles, as well as monolayer protected metal clusters (MPCs) have been reported in the literature. Typically, bulk metal has a system size that is larger than the wavelength of the external electromagnetic field, and its properties can be described with the dielectric functions of the metal. For metal nanoparticles, where the core size is between 3 and $50 \mathrm{~nm}$ in diameter, there is a strong dipolar SPR. The resonance for gold nanoparticles is in the visible region. The majority of the previous optical and detailed electronic characterization studies of metal nanostructures had been focused on the nanoparticles and nanoclusters. ${ }^{1-8}$ Metal clusters had been investigated previously in the gas phase, ${ }^{2,20}$ with the discovery of metal clusters in the condensed phase, a great deal of interest is developed in the application, properties, and fundamental physics of these nanosystems. ${ }^{1,3-8,21-25}$

The interest in nanoparticles by a large following of scientists and engineers focuses on the properties and applications of small

\footnotetext{
${ }^{\dagger}$ Part of the "Protected Metallic Clusters, Quantum Wells and MetalNanocrystal Molecules Symposium" special issue.

* Corresponding author. E-mail: tgoodson@umich.edu.

* University of Michigan.

$\S$ Trinity University.

"Western Michigan University.

${ }^{\perp}$ Current Address: Department of Chemistry, Western Washington University, Bellingham, Washington 98225-9150.
}

metal topologies. In particular, there is a great interest in the possibility that these small clusters of metal $(<2.5 \mathrm{~nm})$ can be used in catalysis, ${ }^{10-15}$ linear and nonlinear optical effects, ${ }^{26-28}$ and "quantized" electrochemical applications. ${ }^{4,9,18,19}$ Although some applications of metal clusters have been well researched, the fundamental science regarding the structure and electronic states are still under debate. There have been a number of different approaches to make small metal clusters. For example, Tomalia et al. ${ }^{29,30}$ reported the first synthesis of smaller gold particles under the context of making dendrimer metal nanocomposites. It was later found with these systems that tremendous optical limiting and time-resolved optical properties ${ }^{31-33}$ could be obtained as well as new ideas for catalysis..$^{9-15}$ Highly stable systems, such as gold, became a major focus for new nanosystem synthesis. ${ }^{34,35}$ The search for even smaller gold particles made in this regard was reported by Crooks et al., ${ }^{36,37}$ Chandler et al..$^{38,39}$ and Dickson et al. ${ }^{7}$ utilizing the dendrimer capture approach with PAMAM. Also, Bauer et al..$^{40}$ utilized a G9 dendrimer (PAMAM) and reported a nanoparticle with size of $\sim 1 \mathrm{~nm}$ as well. Optical studies conducted on this particular dendrimer small metal particle system suggested that the emission (fluorescence) mechanism might vary depending on the size of the metal particle (cluster). ${ }^{33}$ Other synthetic routes were also explored using a ligand-protected approach first explored by the Schmid group. ${ }^{5,41}$ Subsequent progress in the synthetic methods, ${ }^{42-46}$ especially by the Brust group, ${ }^{45}$ has led to well-isolated Au nanoparticles of various distinct sizes ${ }^{47}$ and the production of soluble isolated clusters in large quantities. It was suggested that the nanoparticles produced by the Brust synthesis (and its variations) contain a single layer of ligand shell, leading to the name monolayer protected clusters (MPCs). ${ }^{1,3,5,8}$ Gold nanosystems can be divided into two classes, nanoparticles $(>2 \mathrm{~nm})$ and nanoclusters $(<2 \mathrm{~nm})$, separated by 
size and the presence of surface plasmon resonance (SPR) in the absorption spectrum. The progress in synthesis and purification paved way to the breakthrough of a total structural determination of Au nanoclusters $\mathrm{Au}_{102}(\mathrm{SR})_{44}{ }^{48,49}$ and $\mathrm{Au}_{25}(\mathrm{SR})_{18}{ }^{21,50,51}$ through X-ray crystallography. A number of analytical techniques were also used to understand the composition of the clusters, including HR-TEM, small-angle X-ray scattering, XPS, and thermogravimetric methods. ${ }^{52}$ To understand the physical sizes and distribution of nanosystems, TEM was most commonly used. Identifying clusters using size alone, $\mathrm{Au}_{309},{ }^{53} \mathrm{Au}_{976},{ }^{52}$ $\mathrm{Au}_{55},{ }^{42}$ and others were labeled. As the synthesis techniques advanced, the increase in stability and purity of the samples has led to more sophisticated analytical techniques. In particular, mass spectroscopy proved to be an indispensable tool, identifying not only the core mass but also the ligand shell ratio. $\mathrm{Au}_{25}(\mathrm{SR})_{18},{ }^{54} \mathrm{Au}_{38}(\mathrm{SR})_{24},{ }^{55}$ and $\mathrm{Au}_{144}(\mathrm{SR})_{59}{ }^{55-57}$ were identified using mass spectroscopy. For this article, the clusters will be labeled only with by the core size.

Optical and electrochemical properties have recently been the focus of small metal nanoparticle studies. The emission (fluorescence) properties of a number of gold particle topologies has been investigated. ${ }^{7,27,58-60}$ Very recent results have shown that for a series of small MPCs one can make very impressive two-photon absorbing materials. ${ }^{27}$ Specifically, it was shown that the two-photon cross-section was strongly dependent on the number of gold atoms. ${ }^{27}$ Two-photon fluorescence was observed for the case of small $\mathrm{Au}_{25}$ metal cluster systems for the very first time. ${ }^{27}$ The possibility of fluorescence from gold (or some nonpoisonous metals) particles for medical and imaging applications is immense, and this sheds new light on a limitation that has been an issue in nano (bio) photonics for a long time, but the mechanism of this emission is still not clear. Visible photoluminescence from smooth gold surface was first reported by Mooradian in 1969 and was found to be very inefficient $\left(10^{-10}\right) .{ }^{28}$ In recent years, the attention was turned to near spherical gold nanoparticles and nanorods. Both nanosystems have been reported to have a higher quantum yield ${ }^{59}$ than the thin film gold. The increase in emission can be attributed to local field enhancements. ${ }^{59,60}$ A very fast $(<50 \mathrm{fs})$ depolarized luminescence for gold particles and rods was observed in our previous investigation. ${ }^{59}$ The proposed mechanism for emission is the photogeneration of d-holes ${ }^{61}$ and subsequent recombination of the d-holes with the electrons near the Fermi level, ${ }^{28,62}$ aided by the Auger process and enhanced by local field enhancement. ${ }^{59}$

For small gold nanoclusters, fluorescence was reported previously in the near-infrared showing a typical quantum yield that is much larger than gold surfaces $\left(\sim 10^{-4}\right) .{ }^{27,58,63}$ In many cases, the emissions from nanoclusters have two peaks, one in the visible and one in the NIR. Both peaks have very different intensities; typically, a much stronger peak is observed in the NIR. ${ }^{27,58,63}$ The mechanism of emission has been the focus of many studies; the complexity of nanoclusters and the lack of a definite structure for some of the clusters have added to the challenge of the question. Because of the size of nanoclusters, quantum size effects are also a consideration, ${ }^{64}$ adding complexity to the investigation. Quantum size effect also introduces the idea that the energy structure for clusters should be molecularlike. The emission of small metal clusters and nanoparticles has been studied in many different ways. For example, the Murray group studied the effect of the metal core on the emission through a core exchange reaction between silver and gold and found that the emission is visible only for silver. ${ }^{65}$ In another study, ${ }^{58}$ the NIR emissions for nanoclusters were found to be insensitive to the core size in the 1 to $2 \mathrm{~nm}$ range. Because of the immense potential that nanoclusters hold, it is important to study the fundamental science of nanoclusters, such as the emission mechanism and other optical properties. This article aims to look closely at the optical properties of gold small nanoclusters of sizes $\mathrm{Au}_{25}, \mathrm{Au}_{55}, \mathrm{Au}_{140}$ and larger nanoparticles $\left(\mathrm{Au}_{976}, \mathrm{Au}_{2046}\right)$. The focus is to investigate the mechanism of emission using time-resolved spectroscopy for the 55 atoms case and compare its properties with those of other clusters.

\section{Experimental Section}

A. Sample Preparation. $\mathrm{Au}_{55}$ was prepared by the previously reported methods. ${ }^{40}$ Dodecane-functionalized generation five PAMAM dendrimers were used to capture gold from a $\mathrm{AuCl}_{4}{ }^{-}$solution. The complexed Au cations were subsequently reduced with $\mathrm{NaBH}_{4}$ in $\mathrm{pH} 9.0$ base. Control of the PAMAM generation and metal/dendrimer ratio allows for size control of the templated particles. The dendrimer-encapsulated Au nanoparticles were extracted in an aqueous solution containing tiopronin. The extraction results in $\mathrm{Au}_{55}$ nanoclusters with tiopronin as the outer shell. The sample was initially characterized by UV-visible spectroscopy spectrum, specifically looking for the lack the SPR and the presence of small features in the spectrum. $^{3}$

The synthesis and characterization of other samples used in our experiments such as $\mathrm{Au}_{25}, \mathrm{Au}_{140}, \mathrm{Au}_{309}, \mathrm{Au}_{976}$, and $\mathrm{Au}_{2406}$ were published elsewhere. ${ }^{66,67}$ In brief, metal salts in solution, in this case gold, are reduced with a solution of organic thiols and a phase transfer reagent under temperature-controlled condition to produce MPCs. Typically, a number of analytical techniques such as HR-TEM, small-angle X-ray scattering, XPS, and thermogravimetric analysis are used to characterize MPC; ${ }^{52}$ the sample used in this article was prepared with the same synthesis procedure. ${ }^{66,67}$ Particular samples used in this article were characterized using TEM, ${ }^{66,67}$ where size of the clusters is used to estimate the number of gold atoms and ligands. The assigned core numbers and ligands were derived from the narrow size distributions. ${ }^{66,67}$ Using the results of other characterization recently available, ${ }^{21,50-52,54-57}$ the assigned core number is not perfectly accurate for relatively large clusters with core diameter $>2 \mathrm{~nm}$. For small clusters, recent studies provided accurate compositions. ${ }^{42,54-57}$

B. Steady-State Absorption and Emission. Steady-state absorption and emission measurements were performed at room temperature, with a $1 \mathrm{~mm}$ thick quartz sample cell. All samples were kept in their powder form, under refrigeration, and were dissolved in the appropriate solvent just before the experiments were performed. Optical absorption measurements were carried out using an Agilent 8432 UV-vis absorption spectrometer. Fluorescence measurements were carried out using a Shimadzu RF-1501 spectrofluorophotometer. The quantum yields of the molecules were measured using Coumarin 307 as the standard. To ensure aggregation did not affect the samples, UV-vis spectra were compared before and after the experiment to ensure the purity of the sample. The calculated absorption spectrum utilized the calculation method based on our previous paper following the Gans extension of the Mie theory. ${ }^{59,68,69}$ The dielectric constant of the surrounding medium was taken to be 2 , and the simulated metal system is considered to be spherical with a diameter of particle is $1.1 \mathrm{~nm}\left(\mathrm{Au}_{25}\right)$. The spectrum is calculated from 390 to $800 \mathrm{~nm}$ at $10 \mathrm{~nm}$ intervals.

C. Femtosecond Transient Absorption Measurements. Transient absorption was used to investigate the excited-state dynamics of metal nanoclusters; the experimental setup has been 


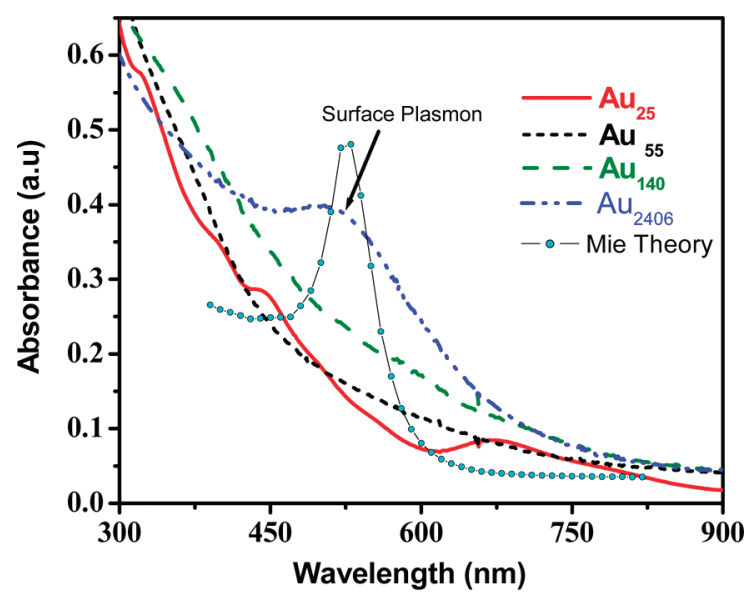

Figure 1. Steady-state absorption for $\mathrm{Au}_{25} \mathrm{Au}_{55}, \mathrm{Au}_{140}$, and Mie theory calculation using parameter similar to $\mathrm{Au}_{25}$.

previously described. ${ }^{26,70,71}$ In brief, the output of an amplified laser beam was split with a beam splitter to generate pump and probe beam pulses ( 85 and 15\%). The pump beam was produced by optical parametric amplifier (OPA-800c). The pump beam used in the present investigation $(390 \mathrm{~nm})$ was obtained from the fourth harmonic of the signal beam and was focused onto the sample cuvette. The probe beam was delayed with a computer-controlled motion controller and then focused into a $2 \mathrm{~mm}$ sapphire plate to generate white light continuum. The white light was then overlapped with the pump beam in a 2 mm quartz cuvette containing the sample, and the change in absorbance for the signal was collected by a CCD detector (Ocean optics). Data acquisition was controlled by the software from Ultrafast Systems. The typical power of probe beam was $<0.1 \mu \mathrm{J}$, whereas the pump beam used was $\sim 0.1$ to $0.4 \mu \mathrm{J}$ per pulse. Magic angle polarization was maintained between the pump and probe using a wave plate. We obtained the instrument response function (IRF) by fitting the solvent response, and it was found to be $\sim 130$ fs. The sample was stirred with a rotating magnetic stirrer, and no photodegradation of the sample was observed.

D. Femtosecond Time-Resolved Fluorescence. The timeresolved fluorescence setup used in our experiments was previously described. ${ }^{27,59}$ Specifically, the sample is excited with frequency doubled or tripled light from a mode-locked Ti-sapphire laser. All samples were held in a $1 \mathrm{~mm}$ thick rotating sample cuvette. Fluorescence emitted from the sample was up-converted in a nonlinear crystal of barium borate (BBO) at $\sim 800 \mathrm{~nm}$ and passed through a variable delay line before upconversion. The IRF has a duration of $\sim 200$ fs for visible excitation. The system also has the capability to carry out ultrafast emission anisotropy decay measurements. The energy per excitation pulse did not exceed $600 \mathrm{pJ}$ for any experiment. Standard dyes were used to calibrate the system. We obtained lifetimes of the fluorescence decay by fitting the experimental profile with multiexponential decay functions convoluted with the IRF. We achieved spectral resolution by using a monochromator and photomultiplier tube.

\section{Results and Discussion}

A. Steady-State Absorption. The steady-state absorption spectra are shown in Figure 1 for $\mathrm{Au}_{25}, \mathrm{Au}_{55}, \mathrm{Au}_{144}$, and $\mathrm{Au}_{2406}$. Because of differences in the size and structure of the nanoclusters and nanoparticles, they have different steady-state absorption spectra, ${ }^{64,72}$ namely, the presence of SPR. ${ }^{59,68,69}$ The

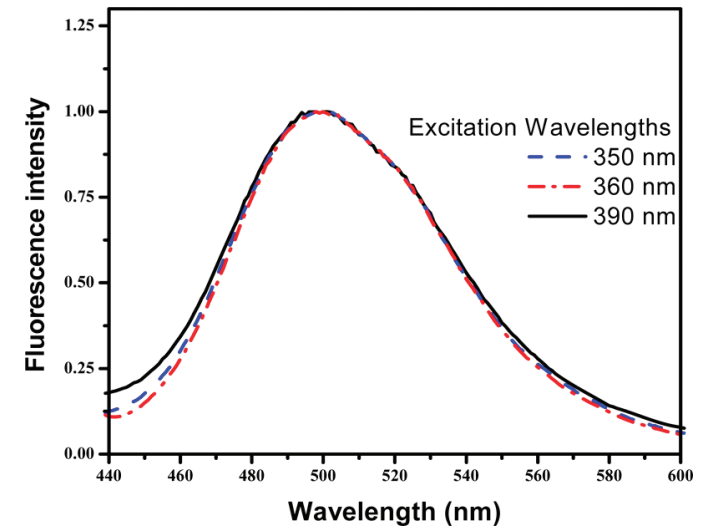

Figure 2. Normalized emission spectra for $\mathrm{Au}_{55}$ excited at 350, 360, and $390 \mathrm{~nm}$.

surface plasmon is caused by the collective response in the polarization and restoration of conductive electrons ${ }^{68,69}$ and can be observed as a peak in the visible spectrum centered at $\sim 520$ $\mathrm{nm}$ for gold nanoparticles. However, SPR is observed only in nanoparticles and not in nanoclusters, and can be used to differentiate between the two systems. From Figure 1, it can be clearly seen that SPR is observed for $\mathrm{Au}_{2406}$, and the lack of SPR for $\mathrm{Au}_{25}, \mathrm{Au}_{55}$, and $\mathrm{Au}_{140}$ confirms that the samples are nanoclusters.

Between the nanoclusters, the difference in core size creates a difference in the electronic structure. As it was reported by Jin et al., ${ }^{21}$ the three distinct features in the absorption spectrum for $\mathrm{Au}_{25}$ can be correlated to the proposed icosahedra structure. ${ }^{23,24}$ In another report, the absorption spectrum is directly affected by the geometric and electronic structure of the system. ${ }^{23,24}$ Utilizing a calculation method based on Mie theory (as was done previously for larger particles), ${ }^{59,68,69}$ the absorption spectrum for a gold system similar in size to $\mathrm{Au}_{25}$ can be simulated. The Mie theory predicts the appearance of a surface plasmon band that is not observed in the experimental results; this suggests that Mie theory does not apply for nanoparticles at very small sizes. Comparing the absorption spectrum of $\mathrm{Au}_{140}$ to that of $\mathrm{Au}_{55}$ or $\mathrm{Au}_{25}$ also offers evidence of a quantum size effect. The strength of the characteristic absorption features increases as the size of the cluster decreases, which suggests that the molecular characteristics may possibly be associated with the size of the core.

B. Fluorescence. We measured fluorescence from samples excited at $390 \mathrm{~nm}$ and found visible emission spectra from the tiopronin-capped $\mathrm{Au}_{55}$ samples with a peak centered at $500 \mathrm{~nm}$ and a quantum efficiency of $1.25 \times 10^{-5}$ (Figure 2). The sample was also excited in the range of $360-390 \mathrm{~nm}$, and the emission peak from each excitation wavelength was detected at $500 \mathrm{~nm}$. With the aid of time-resolved fluorescence upconversion, the emission decay was found to be $\sim 250 \mathrm{fs}$, longer than the IRF of the setup (Figure 3). The emission of $\mathrm{Au}_{55}$ has been an area of interest since its discovery. Crooks et al. ${ }^{36}$ studied dendrimer and other synthetic materials used in the synthesis of $\mathrm{Au}_{55}$ nanoclusters but found them to be nonfluorescent. $\mathrm{Au}_{55}$ emission was also investigated by the Murray group ${ }^{65}$ in an Ag exchange reaction. Their experiment started with Ag MPCs, monitoring the emission as $\mathrm{Ag}$ is exchanged for $\mathrm{Au}$. We observed $500 \mathrm{~nm}$ emission for Ag MPCs and in the steps of the reaction but not for $\mathrm{Au}$. The $\mathrm{Au}_{55}$ sample that was used in our experiments was produced through PAMAM dendrimer exchange reaction process. We observed both steady-state and time-resolved emission from $\mathrm{Au}_{55}$. Fluorescence from $\mathrm{Au}_{25}$ and $\mathrm{Au}_{140}$ has been 


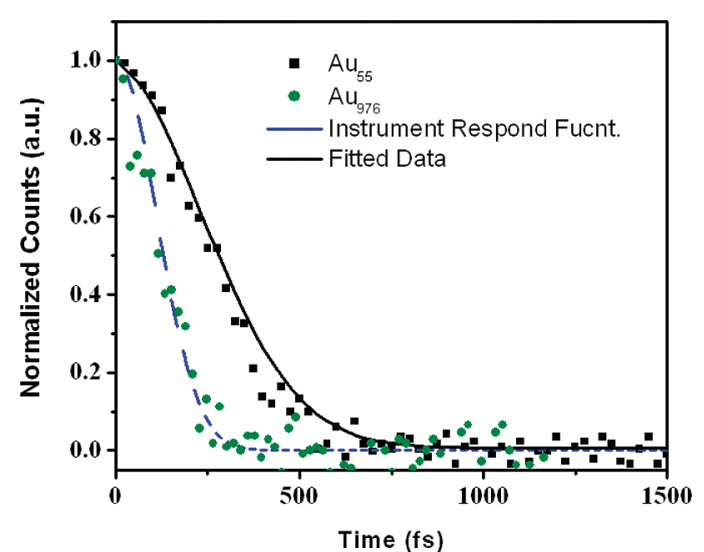

Figure 3. Time-resolved visible emission for $\mathrm{Au}_{55}$ with a lifetime of $\sim 250 \mathrm{fs}$. The blue line shown is the instrument response function.

previously reported but not for $\mathrm{Au}_{55} \cdot{ }^{27,58,64,73}$ The quantum yield (QY) for visible emission of $\mathrm{Au}_{55}$ is significantly larger than the $10^{-10}$ reported for bulk gold. ${ }^{28}$ Compared with the estimated QY for $\mathrm{Au}_{25}$ and the experimental result from $\mathrm{Au}_{140}$, the QY for $\mathrm{Au}_{55}$ is comparable in the visible (Table 1). The infared QY for $\mathrm{Au}_{55}$ is still under investigation; from the observed trend found for $\mathrm{Au}_{25}$, the QY in the NIR for $\mathrm{Au}_{55}$ could be even stronger than the visible emission. ${ }^{27,58,73}$

C. On the Mechanism of Emission. From the emission data, we can identify two luminescence transitions: transition from a short-lived state in the visible range, which is most probably associated with the MPC's core, ${ }^{21,22,59,64}$ and that from a longlived surface-related state in near- infrared most probably associated with ligands. ${ }^{21,22,59,64}$ Our time-resolved fluorescence data showed that the visible emission lifetime ( $\sim 250 \mathrm{fs}$, Figure 3 ) is substantially longer than the lifetime of the visible emission of larger nanoparticles. ${ }^{59}$ The short-lived visible emission mechanism can be explained by the creation of the hole by the excitation in the ground state, which can be subsequently filled with the electron from the higher lying excited state near 2.5 $\mathrm{eV}$ (Figure 4, B band). This transition is similar to the $\mathrm{HOMO}-\mathrm{LUMO}+1$ suggested on the basis of crystal structure for $\mathrm{Au}_{25}(\mathrm{SR})_{18} \cdot{ }^{21,22} \mathrm{HOMO}-\mathrm{LUMO}$ transition corresponds to the transition from ground state to A band on the diagram shown in Figure 4. The energy gap of this transition is lower than that for the observed visible fluorescence. On the basis of the absence of the detected dynamic Stokes shift, it was suggested that the energy is quickly transferred for A band to the long-lived surface-related (semiring) states from which the NIR fluorescence originates. ${ }^{21,22}$ For larger nanoparticles, the photogenerated d-hole is filled by the s-p electron near the Fermi level, which leads to very short-lived (hole lifetime $\sim 20-30 \mathrm{fs}^{61}$ ) visible emission. ${ }^{62}$ The proximity of surface plasmon in terms of energy can enhance the fluorescence, thus leading the higher quantum yield as compared with bulk metal. ${ }^{59}$

Surface states were used in reported literature $22,57,76$ to explain the longer fluorescence lifetime in the NIR for nanoclusters. It was suggested that the A band to ground-state transition is mostly nonradiative and does not produce detectable fluorescence. The observed NIR emission is most probably the transition from the surface state to the ground state. Furthermore, the surface state should be affected by the surface type (ligand), and the surface state should be independent of the core size.

We obtained fluorescence up-conversion lifetimes by fitting the experimental profile with multiexponential decay functions convoluted with the IRF. Comparison of the fluorescence life times between nanoclusters $\left(\mathrm{Au}_{55}, \mathrm{Au}_{25},{ }^{27} \mathrm{Au}_{140},{ }^{27} \mathrm{Au}_{309}{ }^{27}\right)$ and nanoparticles ${ }^{59}$ (Figure 5) shows that the lifetime for nanoclusters is much longer than that for nanoparticles. The difference in the lifetime could be attributed to the fast filling of the d-holes for the nanoparticles, whereas for nanoclusters, a molecularlike discrete energy level structure results in a slower relaxation process. The distinct difference in the lifetime of nanoclusters and nanoparticles is another manifestation of the quantum size effect, showing that as the particle size changes the emission mechanism also changes. Upon a closer inspection of $\mathrm{Au}_{55}$ and $\mathrm{Au}_{976}$ (Figure 3), it can be seen clearly that the lifetime for $\mathrm{Au}_{976}$ is much shorter than that for $\mathrm{Au}_{55}$. Looking at the relationship between quantum yield and fluorescence lifetime, if we assume that both $\mathrm{Au}_{25}$ and $\mathrm{Au}_{976}$ are close in oscillator strength, we can suggest that there will be a correlation between quantum yield and fluorescence lifetime. This relationship is now observed experimentally.

D. Wavelength-Resolved Transient Absorption. Transient absorption allows for studying excited-state dynamics of the chemical system and gives information about the energy states of the system. The transient absorption of nanoparticles and nanoclusters has been previously studied by various groups. ${ }^{26,27,31,64,74-81}$ Our group has also studied the degenerate transient absorption of $\mathrm{Au}_{25}$ and $\mathrm{Au}_{140} \cdot{ }^{27,64}$ In this report, we extend our transient absorption study to wavelength-resolved transient absorption; we have also included $\mathrm{Au}_{55}$ in our investigation. Transient absorption spectra of $\mathrm{Au}_{25}, \mathrm{Au}_{55}$, and $\mathrm{Au}_{140}$ were compared at time delay of $550 \mathrm{fs}$ (Figure 6). All three spectra showed no bleaching at $530 \mathrm{~nm}$, an additional indication of the absence of SPR, which correlates with the steady-state absorption data. For $\mathrm{Au}_{55}$ and $\mathrm{Au}_{25}$, the peak at $500 \mathrm{~nm}$ shows transitions similar in magnitude, whereas $\mathrm{Au}_{140}$ shows a stronger transient absorption at this wavelength. For the transient absorption at $650 \mathrm{~nm}$, the comparison of $\mathrm{Au}_{140}, \mathrm{Au}_{55}$, and $\mathrm{Au}_{25}$ with the same concentration shows that as the core size decreases, the transient absorption signal also decreases. The kinetic data at $640 \mathrm{~nm}$ for $\mathrm{Au}_{55}$ (Figure 7) show an initial quick relaxation to the intermediate state and then a slow decay back to the ground state. The dynamics are very different from those associated with SPR transients following electron-phonon relaxation in large particles. $^{77}$ The decay profile is typical for molecular-like small clusters with single electron process.

E. Pump Power Dependence of Transients. Varying the pump power of transient absorption measurements can give information aboutelectron-electron scattering and electron-phonon relaxation for some nanosystems. ${ }^{77-81}$ It has been reported for gold nanoparticles that the electron-phonon relaxation depends strongly on pump power, ${ }^{59,79,81}$ whereas the signal of electron-electron scattering is only weakly power-dependent. ${ }^{26}$ Electron-electron scattering for the gold nanoparticles can be attributed to the sharing of energy by excited electrons and the thermal relaxation of the electronic gas. ${ }^{76-79}$ For electron-phonon relaxation, it corresponds to the transfer of energy from electron system to the lattice. ${ }^{77-81}$ For nanoclusters, the decrease in the size and the presence of quantum size effects (evident in the absorption spectra) suggests that the simple interpretation of the decay in terms of e/e and e/ph processes similar to bulk metal do not apply. We fit the decay with experimental function for the 2.5 $\mathrm{nm}$ particle and $\mathrm{Au}_{55}$; we can see that there is a lack of power dependence for $\mathrm{Au}_{55}$ when compared with that of the nanoparticle (Figure 8). The difference in power dependence suggests that the relaxation of the system is affected by the discrete energy levels of a molecule-like system but not the thermal relaxation of the electron-phonon system similar to bulk metal. 
TABLE 1: Comparison of Quantum Yield, Excitation Wavelength, and Emission Wavelength of Various Gold Nanoclusters ${ }^{a}$

\begin{tabular}{llll}
\hline & \multicolumn{1}{c}{$\mathrm{Au}_{25}$} & \multicolumn{1}{c}{$\mathrm{Au}_{55}$} & $\mathrm{Au}_{140-145}$ \\
\hline QY $(\%)$ & $2.5 \times 10^{-4^{*}}\left(3.5 \times 10^{-3}\right)$ & $2.5 \times 10^{-5}$ & not reported $\left(4.4 \times 10^{-5}\right)$ \\
excitation $(\lambda)$ & $300-900 \mathrm{~nm}(800 \mathrm{~nm})$ & $390 \mathrm{~nm}$ & $400 \mathrm{~nm}(1064 \mathrm{~nm})$ \\
emission $(\lambda)$ & $500 \mathrm{~nm}(1100 \mathrm{~nm})$ & $500 \mathrm{~nm}$ & $525 \mathrm{~nm}(1100-1600 \mathrm{~nm})$
\end{tabular}

${ }^{a}$ Values in parentheses are for fluorescence in the near infared..$^{27,58,65,73}$

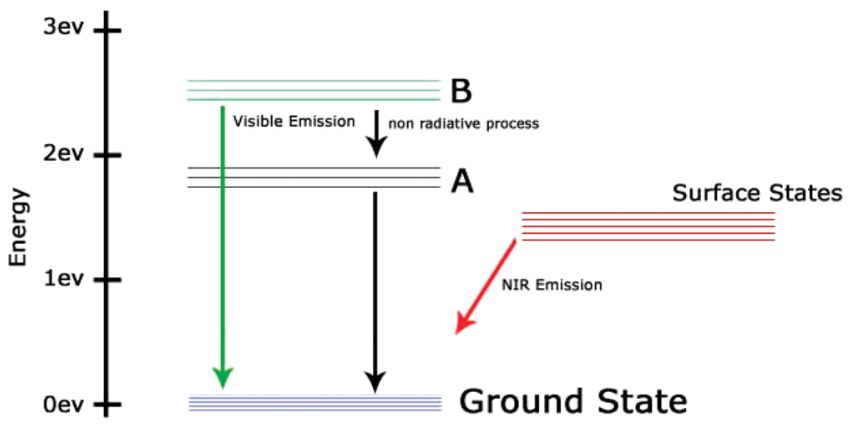

Figure 4. Transition-energy diagram for the emissions for MPCs using data from steady-state emission, fluorescence upconversion, and transient absorption.

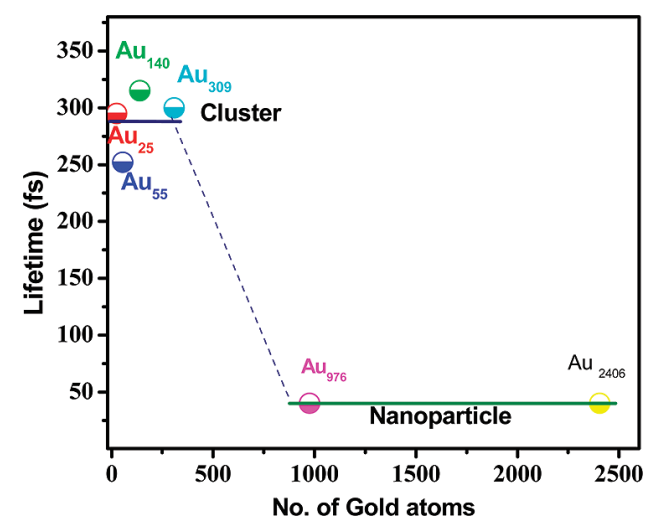

Figure 5. Fluorescence lifetime comparisons for MPCs of various sizes. The most notable difference is between the nanoparticle and nanoclusters.

F. Bleach Structure. The energy structure for nanocluster $\mathrm{Au}_{25}$ has been studied by various groups. Zhu et al. ${ }^{21}$ performed time-dependent density functional theory calculations based on structural information and correlated the calculated result to the experimentally measured absorption spectrum. Moran et $\mathrm{al}^{22}$ used transient absorption experiments to investigate the relaxation processes in $\mathrm{Au}_{25}(\mathrm{SR})_{18}$. The analysis of the transient absorption data in this work $^{22}$ showed that the bleaching observed at $\sim 680 \mathrm{~nm}$ corresponds to a HOMO-LUMO absorption peak and can be assigned to the ground-state bleach. Transient absorption spectrum accessible by our setup covers the range from 450 to $750 \mathrm{~nm}$, which is broader than the 620-800 nm range accessible by Moran et al. ${ }^{22}$ In our experiments, we also observed the dip in transient absorption spectrum near $680 \mathrm{~nm}$ (Figure 9). Because of extended spectral range, we were also able to detect another dip near $550 \mathrm{~nm}$ (Figure 9). Using similar analysis, ${ }^{22}$ we can suggest that the weakly negative dip in transient absorption spectrum near 550 $\mathrm{nm}$ corresponds to the bleach of another transition from the ground state near $2.25 \mathrm{eV}$ due to the ground-state population depletion. This transition could be correlated to the weak shoulder observed in the steady-state absorption spectrum (Figure 10).

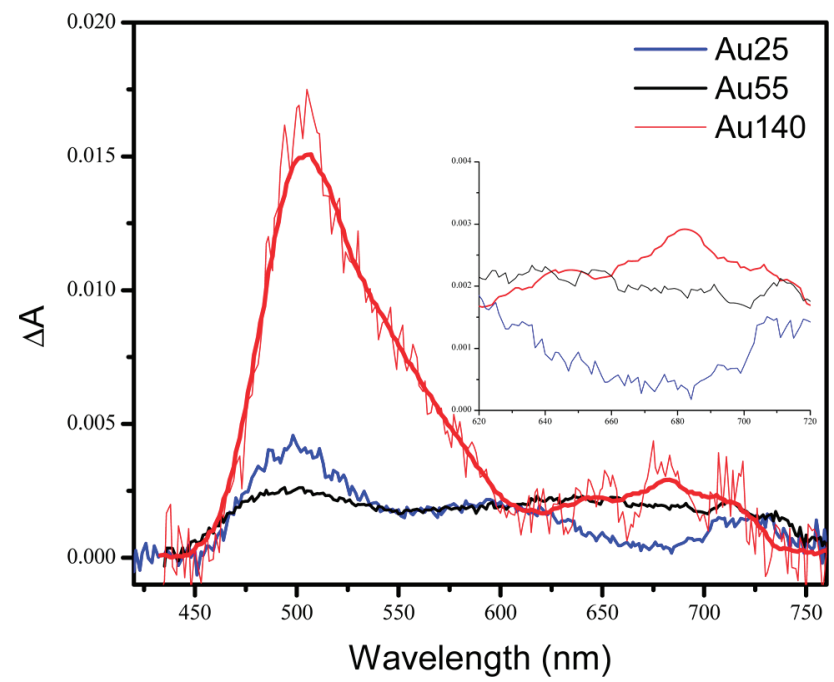

Figure 6. Transient absorption for $\mathrm{Au}_{25}, \mathrm{Au}_{55}$, and $\mathrm{Au}_{140}$ at $550 \mathrm{fs}$. The transient absorption near $675 \mathrm{~nm}$ is highlighted in the inset.

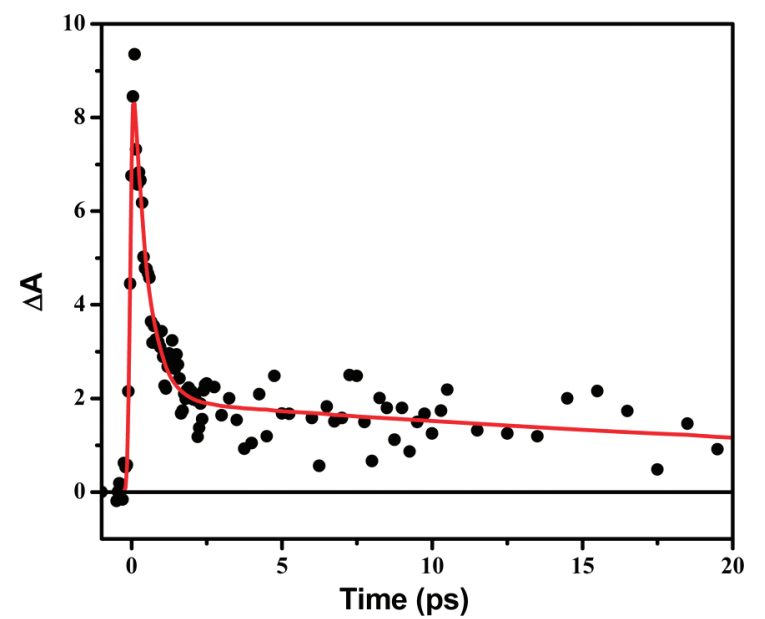

Figure 7. Kinetic data from transient absorption for $\mathrm{Au}_{55}$ at $640 \mathrm{~nm}$.

\section{Summary}

In summary, the emission for $\mathrm{Au}_{55}$ has been observed in the visible range. It was time-resolved on a subpicosecond time scale using fluorescence upconversion. The visible emission from $\mathrm{Au}_{55}$ is much stronger than that observed for larger nanoparticles. The mechanism of emission was investigated and was found to be different from that for larger nanoparticles and bulk gold. In particular, the existence of molecular-like emission with considerably stronger intensity became evident for the $\mathrm{Au}_{55}$ system. This provides stronger evidence of the presence of quantum size effects, which were observed by comparing absorption spectra and fluorescence decay profiles for nanoparticles and nanoclusters. The transient absorption dynamics of $\mathrm{Au}_{55}$ was found to be nearly independent of the pump power, which was very different from those observed for larger nanoparticles. Close inspection of transient absorption spectra, and the steadystate absorption of $\mathrm{Au}_{25}$ suggests the existence of another state 


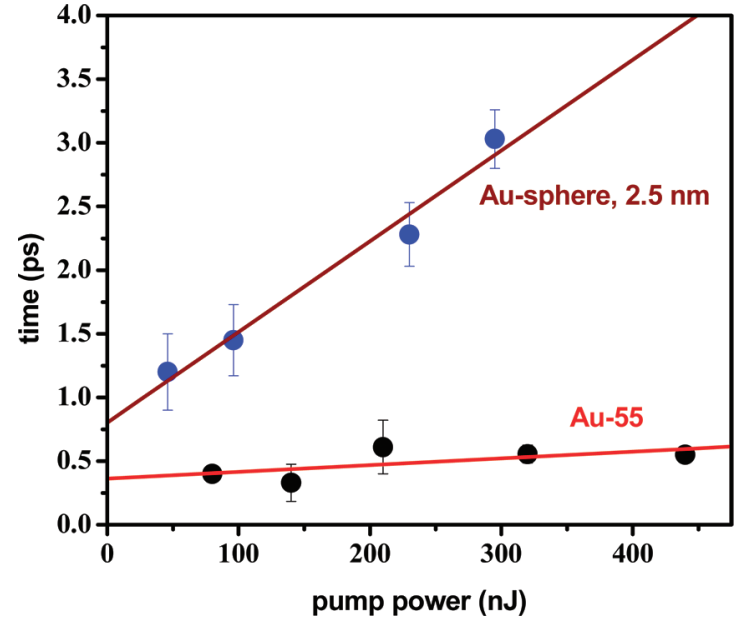

Figure 8. Pump power dependence against average lifetime for 2.5 $\mathrm{nm}$ particle and $\mathrm{Au}_{55}(1.4 \mathrm{~nm})$.

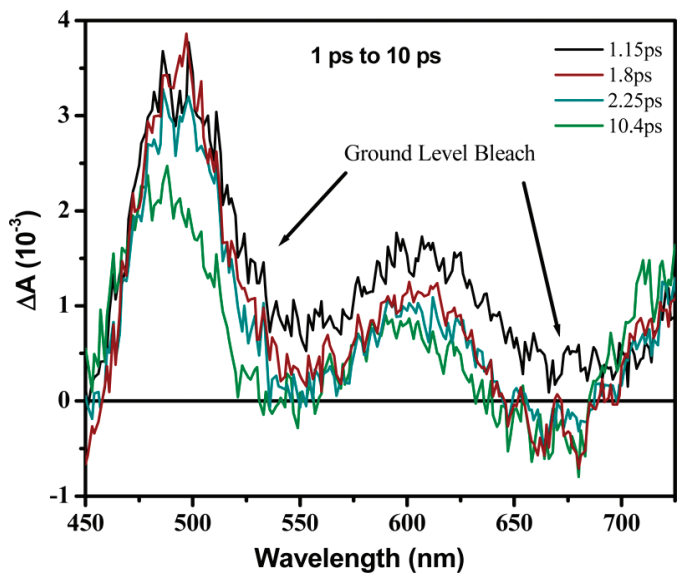

Figure 9. Transient absorption comparison data for $\mathrm{Au}_{25}$ in hexane probed from $450 \mathrm{~nm}$ to $750 \mathrm{~nm}$. An extra feature at $550 \mathrm{~nm}$ can be observed.

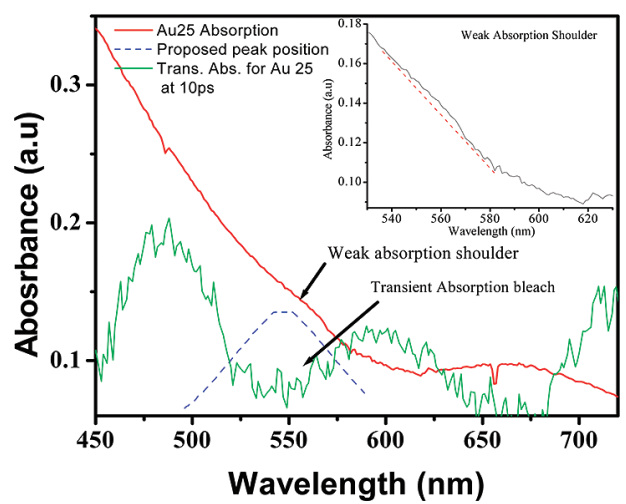

Figure 10. Steady-state absorption highlighting the proposed state.

not previously considered. The valley at $\sim 550 \mathrm{~nm}$ from the transient absorption spectrum may correspond to the bleach of the transition to this state from the ground state due to the ground-state depletion, similar to that observed at $\sim 680 \mathrm{~nm}$.

\section{References and Notes}

(1) Templeton, A.; Wuelfing, P.; Murry, R. Acc. Chem. Res. 2000, 33,

(2) de Heer, W. A. Rev. Mod. Phys. 1993, 65, 611.

(3) Murray, R. Chem. Rev. 2008, 108, 2688.

(4) Daniel, M.; Astruc, D. Chem. Rev. 2003, 104, 293.
(5) Schmid, G. Chem. Soc. Rev. 2008, 37, 1909.

(6) Pyykko, P. Chem. Soc. Rev 2008, 37, 1967.

(7) Zheng, J.; Zhang, C.; Dickson, M. Phys. Rev. Lett. 2004, 93 , 077402

(8) Walter, M.; Akola, J.; Lopez-Aceedo, O.; Jadzinsky, P. D.; Calero, G.; Ackerson, C. J.; Whetten, R. L.; Gronbeck, H.; Hakkinen, H. Proc. Natl. Acad. Sci. U.S.A 2008, 105, 9157.

(9) Antonello, S.; Holm, A. H.; Instuli, E.; Maran, F. J. Am. Chem. Soc. 2007, 129, 9836. 3481

(11) Zheng, N.; Stucky, G. D. J. Am. Chem. Soc. 2006, 128, 14278.

(12) Valden, M.; Lai, X.; Goodman, D. W. Science 1998, 281, 1647.

(13) Tuner, M.; Golovoko, V. B.; Vaughan, O. P. H.; Abdulkin, P.; Berenguer-Murcia, A.; Tikhov, M. S.; Johnson, B. F. G.; Lamber, R. M. Nature 2008, 454, 981.

(14) Long, C. G.; Gilbertson, J. D.; Vijayaraghavan, G.; Stevenson, K. J.; Pursell, C. J.; Chandler, B. D. J. Am. Chem. Soc. 2008, 130, 10103.

(15) Lang, H.; May, R. A.; Iversen, B. L.; Chandler, B. D. J. Am. Chem. Soc. 2003, 125, 14832.

(16) Hainfield, J. F. Science. 1987, 236, 450.

(17) Nam, J. M.; Thaxton, C. S.; Mirkin, C. A. Science. 2003, 301, 1884.

(18) Wohltjen, H.; Snow, A. W. Anal. Chem. 1998, 70, 2856.

(19) Chen, S. W.; Ingram, R. S.; Hostetler, M. J.; Pietron, J. J.; Murray, R. W.; Schaaff, T. G.; Khoury, J. T.; Alvarez, M. M.; Whetten, R. L. Science 1998, 280, 2098

(20) Fackler, J. P. Jr.; McNeal, C. J.; Pignolet, L. H.; Winpenny, R. E. P. J. Am. Chem. Soc. 1989, 11, 6434.

(21) Zhu, M.; Aikens, C. M.; Hollander, F. J.; Schatz, G. C.; Jin, R. J. Am. Chem. Soc. 2008, 130, 5883.

(22) Miller, S. A.; Womick, J. M.; Parker, J. F.; Murray, R. W.; Moran, A. M. J. Phys. Chem. C 2009, 113, 9440.

(23) Aikens, C. M. J. Phys. Chem. C 2008, 112, 19797.

(24) Aikens, C. M. J. Phys. Chem. A 2009, 113, 10811.

(25) McNeal, C. J.; Hughes, J. M.; Pignolet, L. H.; Nelson, L. T. J.; Gardner, T. G.; Fackler, J. P.; Winpenny, R. E. P.; Irgens, L. H.; Vigh, G.; Macfarlane, R. D. Inorg. Chem. 1993, 32, 5582.

(26) Ramakrishna, G.; Dai, Q.; Zou, J.; Huo, Q.; Goodson, T. J. Am. Chem. Soc. 2007, 129, 1848.

(27) Ramakrishna, G.; Varnavski, O.; Kim, J.; Lee, D.; Goodson, T. J. Am. Chem. Soc. 2008, 130, 5032.

(28) Mooradian, A. Phys. Rev. Lett. 1969, 22, 185.

(29) Balogh, L.; Valluzzi, R.; Laverdure, K. S.; Gido, S. P.; Hagnauer,

G. L.; Tomalia, D. A. J. Nanopart. Res. 1999, 1, 353.

(30) Chen, W.; Tomalia, D. A.; Thomas, J. L. Macromolecules. 2000, 33,9169 .

(31) Smith, B A.; Zhang, J Z.; Giebel, U.; Schmid, G. Chem. Phys. Lett. 1997, 270, 139.

(32) Ispasoiu, R. G.; Balogh, L.; Varnavski, O. P.; Tomalia, D. A.; Goodson, T. J. Am. Chem. Soc. 2000, 122, 11005.

(33) Goodson, T., III.; Varnavski, O.; Wang, Y. Int. Rev. Phys. Chem. 2004, 23, 109.

(34) Negishi, Y.; Chaki, N. K.; Shichibe, Y.; Whetten, R. L.; Tsukuda,

T. J. Am. Chem. Soc. 2007, 129, 11322 .

(35) Echt, O.; Sattler, K.; Recknagel, E. Phys. Rev. Lett. 1981, 47, 1121.

(36) Kim, T.; Oh, S.; Crooks, R. Chem. Mater. 2004, 16, 167.

(37) Knecht, M. R.; Garcia-Martinez, J. C.; Crooks, R. M. Langmuir 2005, 21, 11981

(38) Korkosz, R. J.; Gilbertson, J. D.; Parsifka, K. S.; Chandler, B. D. Catal. Today 2007, 122, 370.

(39) Gilbertson, J. D.; Vijayaraghavan, G.; Steverson, K. J.; Chandler, B. D. Langmuir 2007, 23, 11239.

(40) Gröhn, F.; Bauer, B. J.; Akpalu, Y. A.; Jackson, C. L.; Amis, E. J. Macromolecules 2000, 33, 6042.

(41) Schmid, G.; Boese, R.; Pfeil, R.; Bandermann, F.; Mayer, S.; Calis, G. H. M.; Vandervelden, J. W. A. Chem. Ber. 1981, 114, 3634.

(42) Tsunoyama, H.; Negishi, Y.; Tsukuda, T. J. Am. Chem. Soc. 2006, 128, 6036 .

(43) Brust, M.; Fink, J.; Bethell, D.; Schiggrin, D. J.; Kiely, C. J. Chem. Soc., Chem. Commun. 1995, 1655.

(44) Donkers, R. L.; Lee, D.; Murray, R. W. Langmuir 2004, 20, 1945.

(45) Brust, M.; Walker, M.; Bethel, D.; Schiffrin, D. J.; Whyman, R. J. Chem. Soc. Chem. Commun 1994, 801.

(46) Schaaff, T. G.; Knight, G.; Shafigullinr, M. N.; Borkman, R. F.; Whetten, R. L. J. Phys. Chem. B 1998, 102, 10643.

(47) Alvarez, M. M.; Khoury, J. T.; Schaaff, T. G.; Shafigullin, M.; Vezmar, I.; Whetten, R. L. Chem. Phys. Lett. 1997, 266, 91.

(48) Jadzinsky, P. D.; Calero, G.; Ackerson, C. J.; Bushnell, D. A.; Kornberg, R. D. Science 2007, 314, 430.

(49) Whetten, R. L.; Price, R. C. Science 2007, 318, 407.

(50) Heaven, M. W.; Dass, A.; White, P. S.; Holt, K. M.; Murray, R. W. J. Am. Chem. Soc. 2008, 130, 3754. 
(51) Akola, J.; Walter, M.; Whetten, R. L.; Hakkinen, H.; Gronbeck, H. J. Am. Chem. Soc. 2008, 130, 3756.

(52) Hostetler, M. J.; Wingate, J. E.; Zhong, C.-J.; Harris, J. E.; Vachet,

R. W.; Clark, M. R.; Londono, J. D.; Green, S. J.; Stokes, J. J.; Wignall, G. D.; Glish, G. L.; Porter, M. D.; Evans, N. D.; Murray, R. W. Langmuir 1998, $14,17$.

(53) Curley, B. C.; Johnston, R. L.; Yong, N. P.; Li, Z. Y.; Vece, M. D.; Palmer, R. E.; Bleloch, A. L. J. Phys. Chem. C 2007, 111, 17846.

(54) Dass, A.; Dubay, G. R.; Fields-Zinna, C. A.; Murray, R. W. Anal. Chem. 2008, 80, 6845 .

(55) Chaki, N. K.; Negishi, Y.; Tsunoyama, H.; Shichibu, Y.; Tsukuda,

T. J. Am. Chem. Soc. 2008, 130, 8608.

(56) Huifeng, Q.; Jin, R. Nano Lett 2009, 12, 4083.

(57) Lopez-Acevedo, O.; Akola, J.; Whetten, R. L.; Gronebeck, H.; Hakkinen, H. J. Phys. Chem. C 2009, 113, 5035.

(58) Wang, G.; Huang, T.; Murray, R. W.; Menard, L.; Nuzzo, R. G.

J. Am. Chem. Soc. 2004, 127, 812.

(59) Varnavski, O. P.; Goodson, T., III; Mohamed, M. B.; El-Sayed, M. A. Phys. Rev. B 2005, 72, 235405.

(60) Mohamed, M B.; Volkov, V.; Link, S.; El-Sayed, M A. Chem. Phys. Lett. 2000, 317, 517.

(61) Petek, H.; Nagano, H.; Weida, M. J.; Ogawa, S. Chem. Phys. 2000, $251,71$.

(62) Apell, P.; Monreal, R.; Lundqvist, S. Phys. Scr. 1988, 38, 174.

(63) Negishi, Y.; Nobusada, K.; Tsukuda, T. J. Am. Chem. Soc. 2005, 127,5261 .

(64) Varnavski, O.; Ramakrishna, G.; Kim, J.; Lee, D.; Goodson, T.

J. Am. Chem. Soc. 2010, 132, 16.

(65) Huang, T.; Murray, R. W. J. Phys. Chem. B 2003, 107, 7434.

(66) Kim, J.; Lee, D. J. Am. Chem. Soc. 2006, 128, 4518.

(67) Kim, J.; Lee, D. J. Am. Chem. Soc. 2007, 129, 7706.

(68) Gans, R. Ann. Phys. (Paris, Fr.) 1915, 47, 270.
(69) Mie, G. Ann. Phys. 1908, 25, 377.

(70) Ramakrishna, G.; Goodson, T., III; Rogers-Haley, J. E.; Cooper, T. M.; McLean, D. G.; Urbas, A. J. Phys. Chem. C 2009, 113, 1060.

(71) Ramakrishna, G.; Bhaskar, A.; Bauerle, P.; Goodson, T., III. J. Phys. Chem. A 2008, 112, 2018.

(72) Wyrwas, R. B.; Alvarez, M. M.; Khoury, J. T.; Price, R. C.; Schaaff, T. G.; Whetten, R. L. Eur. Phys. J. D 2007, 43, 91.

(73) Bigioni, T. P.; Whetten, R. L.; Dag, O. J. Phys. Chem. B 2000, 104, 6983.

(74) Logunov, S. L.; Ahmadi, T. S.; El-Sayed, M. A.; Khoury, J. T.; Whetten, R. L. J. Phys. Chem. B 1997, 101, 3713.

(75) Link, S.; El-Sayed, M. A.; Schaaff, T. G.; Whetten, R. L. Chem. Phys. Lett. 2002, 356, 240.

(76) Bigot, J Y.; Merle, J C.; Cregut, O.; Daunois, A. Phys. Rev. Lett. 1995, 75, 4702 .

(77) Voisin, C.; Christofilos, D.; Loukakos, P. A.; Del Fatti, N.; Vallee, F.; Gaundry, M.; Cottancin, E.; Lerme, J.; Pellanin, M.; Broyer, M. Phys. Rev. B 2004, 69, 165416.

(78) Voisin, C.; Del Fatti, N.; Christofilos, D.; Vallée, F. J. Phys Chem. B 2001, 105, 2264.

(79) Voisin, C.; Christofilos, D.; Del Fatti, N.; Vallee, F.; Prevel, B.; Cottancin, E.; Lerme, J.; Pellanin, M.; Broyer, M. Phys. Rev. Lett. 2000, $85,2200$.

(80) Arbouet, A.; Voisin, C.; Christofilos, D.; Langot, P.; Del Fatti, N.; Vallee, F.; Lerme, J.; Celep, G.; Cottancin, E.; Gaudry, M.; Pellanin, M.; Broyer, M.; Maillard, M.; Pileni, M. P.; Treguer, M. Phys. Rev. Lett. 2003, 90, 177401.

(81) Hodak, J H.; Henglein, A.; Hartland, G V. J. Chem. Phy. 2000, 112,5942 .

JP101420G 